\title{
ORIGINAL ARTICLE Reliability, validity and sensitivity to change of neurogenic bowel dysfunction score in patients with spinal cord injury
}

\author{
D Erdem ${ }^{1}$, D Hava ${ }^{1}$, P Keskinoğlu ${ }^{2}$, Ç Bircan ${ }^{1}$, Ö Peker ${ }^{1}, K_{\text {Krogh }}^{3}$ and S Gülbahar ${ }^{1}$
}

Study design: Psychometrics study.

Objectives: The aim of this study is to investigate the validity, reliability and sensitivity to change of neurogenic bowel dysfunction (NBD) score.

Setting: Dokuz Eylül University Faculty of Medicine, Turkey.

Methods: The study included 42 patients with spinal cord injury (SCI). The reliability of NBD score was assessed by test-retest reliability and internal consistency. Cronbach's alpha coefficient was calculated to determine internal consistency. The construct validity was evaluated by exploring correlations between the NBD score and SF-36 scales, patient assessment of impact of NBD on quality of life (QoL) and the physician global assessment (PGA). The Global Rating of Change (GRC) scale was used to assess the change of NBD to investigate the sensitivity of the score to change.

Results: Cronbach's alpha coefficient was 0.547. In test-retest reliability analysis, high correlations between total test-retest NBD score and answers of each question were found $(r=1.000, P<0.001)$. NBD score had a strong and significant correlation with PGA $(r=0.98, P<0.000)$ and the impact on QoL $(r=0.92, P<0.001)$. There was a significant negative correlation between NBD score and subscales of SF-36 $(P<0.05)$ except physical functioning, physical role functioning and physical component summary score. There was a significant improvement in NBD scores after treatment $(P=0.011)$. A significant positive correlation was found between GRC scale and change in total NBD score $(r=0.821, P=0.007)$.

Conclusion: The Turkish version of the NBD score is a valid and reliable instrument and also sensitive to change in patients with SCI. Spinal Cord (2017) 55, 1084-1087; doi:10.1038/sc.2017.82; published online 11 July 2017

\section{INTRODUCTION}

Neurogenic bowel includes colorectal and anal sphincter dysfunction caused by various disorders affecting central nervous system. ${ }^{1}$ Thus, neurogenic bowel dysfunction (NBD) is a common problem in most patients with spinal cord injury $(\mathrm{SCI}) .^{2-5}$ Colorectal transit times are usually prolonged $^{6-9}$ and anorectal sensibility and voluntary control of the external anal sphincter are reduced or lost.7,10,11 Constipation, fecal incontinence and abdominal pain or discomfort are the symptoms of NBD. A recent research reported that $50 \%$ of patients with SCI had moderate to severe symptoms of NBD and that NBD is associated with health-related quality of life (QoL). ${ }^{12}$

There are several scores for clinical assessment of constipation or fecal incontinence, ${ }^{13-15}$ but these scores have not been validated in patients with SCI, as most patients with SCI suffer from both constipation and fecal incontinence. For this reason, there is need for validated standardized symptom-based score that evaluates severity of NBD quantitatively in patients with SCI.

The NBD Score is a symptom-based score that has been developed by Krogh et al. ${ }^{16}$ to evaluate the severity of colorectal dysfunction clinically in patients with SCI. The NBD score is a questionnaire consisting of 10 items that are associated with impaired QoL caused by bowel symptoms, including frequency of defecation ( $0-6$ points), time used for each defecation (0-7 points), uneasiness or headache or perspiration during defecation ( $0-2$ points), regular use of tablets against constipation (0-2 points), regular use of drops against constipation (0-2 points), digital stimulation or evacuation of the anorectum (0-6 points), frequency of fecal incontinence (0-13 points), medication against fecal incontinence ( $0-4$ points), flatus incontinence ( $0-2$ points) and perianal skin problems ( $0-3$ points). The overall NBD score ranges between 0 and 47 points. A higher score indicates more severe bowel symptoms. The severity level of NBD is divided into four subgroups based on the scores: very minor NBD (0-6); minor NBD; ${ }^{7-9}$ moderate NBD; ${ }^{10-13}$ and severe NBD (14 and more). The validity and reproducibility of the NBD score has been established in patients with SCI. ${ }^{16}$

The NBD score has been translated into several languages and recently used in several research on symptoms, pathophysiology and management of NBD in SCI. ${ }^{17-24}$

Finally, NBD score has been added to the International SCI Bowel Function Basic Data Set (Version 2.0) that is a simple, standardized tool developed for the collection and reporting of a minimal amount of information on bowel function in daily practice and research. ${ }^{25}$ However, the studies investigating the validity and reliability of NBD score are still limited, and there is no study that showed the sensitivity to change of NBD score.

${ }^{1}$ Department of Physical Medicine and Rehabilitation, Dokuz Eylül University, Faculty of Medicine, Izmir, Turkey; ${ }^{2}$ Department of Biostatics and Medical Informatics, Dokuz Eylül University Faculty of Medicine, Izmir, Turkey and ${ }^{3}$ Neurogastroenterology Unit, Department of Hepatology and Gastroenterology, Aarhus University Hospital, Aarhus, Denmark Correspondence: Dr D Erdem, Department of Physical Medicine and Rehabilitation, Dokuz Eylül University Faculty of Medicine, Izmir 35340, Turkey.

E-mail: didem_blue86@hotmail.com or didem.erdem86@gmail.com

Received 12 April 2017; revised 5 June 2017; accepted 7 June 2017; published online 11 July 2017 
The aim of this study is to investigate the validity, reliability and sensitivity to change of the Turkish version of NBD score and to make a contribution to the validation of the NBD score.

\section{PATIENTS AND METHODS}

The study included 42 patients with SCI who were admitted to the Department of Physical Medicine and Rehabilitation, Dokuz Eylül University Faculty of Medicine between May 2014 and May 2015. The exclusion criteria were as follows: less than 6 months since injury, cauda equina lesions, head injury or multiple traumas, and cognitive deficits.

Demographic and clinical variables and severity of SCI according to the ASIA impairment scale were noted. The QoL was assessed with the SF-36 questionnaire; ${ }^{26}$ the impact of NBD on QoL was assessed with a 5-point Likert scale. The physician global assessment (PGA) was recorded on a $10 \mathrm{~cm}$ visual analog scale.

Translation, back translation and cross-cultural adaptation of the NBD score into Turkish was done according to the suggested guidelines. ${ }^{27,28}$ The NBD score was translated into Turkish by two Turkish physiatrists who are proficient in English and a naive translator. English back-translations from Turkish were completed, separately, by two official linguists with English as their mother

Table 1 Clinical and demographic characteristics of patients with $\mathrm{SCl}$

\begin{tabular}{|c|c|c|}
\hline Variables & Patients $(n=42)$ & Percentage (\%) \\
\hline \multicolumn{3}{|l|}{ Age (years) } \\
\hline$<30$ & 16 & 38 \\
\hline $30-45$ & 11 & 26 \\
\hline$>45$ & 15 & 36 \\
\hline \multicolumn{3}{|l|}{ Gender } \\
\hline Female & 8 & 19 \\
\hline Male & 34 & 81 \\
\hline \multicolumn{3}{|l|}{ Cause of injury } \\
\hline Traffic accident & 21 & 50 \\
\hline Firearm injury & 4 & 10 \\
\hline Falling down & 11 & 26 \\
\hline Crushing under weight & 3 & 7 \\
\hline Diving into shallow water & 1 & 2 \\
\hline Others & 2 & 5 \\
\hline \multicolumn{3}{|l|}{ Age at injury (years) } \\
\hline$<30$ & 19 & 45 \\
\hline $30-45$ & 11 & 26 \\
\hline$>45$ & 12 & 29 \\
\hline \multicolumn{3}{|l|}{ Time since injury (years) } \\
\hline$\leqslant 1$ & 15 & 36 \\
\hline $2-5$ & 17 & 41 \\
\hline $6-9$ & 6 & 14 \\
\hline$\geqslant 10$ & 4 & 10 \\
\hline \multicolumn{3}{|l|}{ Level of injury } \\
\hline Cervical & 12 & 29 \\
\hline Thoracic & 24 & 57 \\
\hline Lumbar & 6 & 14 \\
\hline \multicolumn{3}{|l|}{ Severity of injury } \\
\hline ASIA A & 23 & 55 \\
\hline ASIA B & 4 & 10 \\
\hline ASIA C & 11 & 26 \\
\hline ASIA D & 4 & 10 \\
\hline
\end{tabular}

Abbreviation: SCl, spinal cord injury. tongue and who have no prior knowledge of the original version of the NBD score. An expert committee consisting of a methodologist, all forward and backward translators (health professionals, language professionals) met to discuss and decide on the translations. The committee has reviewed all the translations and reached a consensus on any discrepancy and finally developed the prefinal version that was tested in the field. This prefinal Turkish version was tested on 20 spinal cord-injured patients and healthy subjects to determine whether they could understand all the items in the Turkish-NBD score. The Turkish version of NBD score was found understandable by patients and healthy subjects and distinctive for both groups, and the final form of the Turkish version of NBD score was formed at the end of this study. ${ }^{29}$

\section{Reliability study for the Turkish version of NBD score}

The reliability of NBD score was assessed by internal consistency and test-retest reliability.

Test-retest application. Patients refilled the questionnaires 1-2 weeks after the first evaluation in order to determine test-retest reliability. The correlation between previous and latter measurements of every question and total NBD scores in test-retest application were evaluated. Also, the consistency analysis was evaluated with kappa statistics in the frequency distributions of the answers to every question.

Internal consistency. NBD score is not a Likert type scale, but the additivity of the total score was tested with Tukey's nonadditivity test and the additivity characteristic was demonstrated. Due to the presence of additivity characteristic of the test and ordinal characteristic of the answers, Cronbach alpha coefficient was calculated to determine the reliability of internal consistency.

\section{Validity study for the Turkish version of NBD score}

No golden standard test is available to be used to determine the criterion validity of NBD score. Data structure of the test is not appropriate for factor analysis. Thus, construct validity of NBD score was assessed with the correlation of score with SF-36, PGA and patient assessment of impact on the QoL.

Also the patients were divided into two groups according to their NBD scores: NBD score between 0 and 9 was classified as mild and a score of 10 and above was classified as significant NBD. The difference between SF-36 scores of both groups was evaluated with Mann-Whitney $U$ test, and a validity evaluation was done by testing whether NBD degree predicted the difference in QoL.

\section{Sensitivity to change study for NBD score}

The patients with moderate dysfunction (NBD score 10-13) and severe dysfunction (NBD score $\geqslant 14$ ) were selected, and both neurogenic bowel program and patient education were given. At the end of 2 months, the Global Rating of Change (GRC) scale was used to assess the change of NBD. ${ }^{30}$ The significance of change in total NBD scores at the end of 2 months was evaluated with Wilcoxon test and also a correlation analysis was done between Global Rating of Change scale and improvement of total NBD scores.

Spearman's correlation coefficient was used to assess the relation between quantitative parameters. $P<0.05$ was considered as statistically significant. SPSS (Statistical package for social sciences for Windows 15.0) program was used for the statistical analysis of all data acquired.

The study was approved by the Ethical Committee. We certify that all applicable institutional and governmental regulations concerning the ethical use of human volunteers were followed during the course of this research.

\section{RESULTS}

Demographic and clinical data of the 42 patients included are demonstrated in Table 1 . The mean age of patients was $39 \pm 16$ years.

The median (min-max) values of the NBD score was 15.1 (range 11-21). The bowel dysfunction subgroups according to NBD score are given in Table 2 . 
Table 2 Bowel dysfunction subgroups of patients according to NBD score

Bowel dysfunction according to NBD Scores Number $(n=42) \quad$ Percentage (\%)

\begin{tabular}{lcc}
\hline Very minor & 16 & 38 \\
Minor & 14 & 33 \\
Moderate & 4 & 10 \\
Severe & 8 & 19
\end{tabular}

Abbreviation: NBD, neurogenic bowel dysfunction.

Reliability analyses for the Turkish version of NBD score

Cronbach's alpha coefficient for internal consistency was 0.547. In test-retest reliability analysis, there were high correlations between test-retest total NBD score and also test-retest answers of each question $(r=1.000, P<0.001)$. The consistency of frequency distribution of all answers for each item was analyzed by kappa statistics and very high consistency was found $(\kappa=1.000, P<0.001)$.

It revealed acceptable reliability.

Validity analyses for the Turkish version of NBD score

As for the correlations between total NBD score and SF-36 subscales, a statistically significant negative correlation was detected between bodily pain $(r=-0.382, P=0.013)$, general health $(r=-0.560$, $P<0.001)$, vitality $(r=-0.626, P<0.001)$, social role functioning (SF) $(r=-0.741, P<0.001)$, emotional role functioning $(r=-0.604$, $P<0.001)$ and mental health $(r=-0.687, P<0.001)$ subscales, whereas no significant correlation was found with physical functioning (PF) $(r=-0.233, P=0.138)$ and physical role functioning (RP) $(r=0.067, P=0.674)$ subscales of SF-36. The highest correlation among these was found in the social function subscale. The total NBD score had strong and significant negative correlation with the mental component summary score (MCS) $(r=-0.872, P<0.001)$ and had no significant correlation with the physical component summary score (PCS) $(r=-0.187, P=0.235)$.

There was a significant positive correlation between NBD total score and PGA $(r=0.91, P<0.001)$. A positive correlation was found between NBD total score and patients' assessment of impact of NBD on QoL $(r=0.92, P<0.001)$.

The patients were divided into two groups according to their NBD scores: NBD scores between 0 and 9 were classified as mild and scores of 10 and above were classified as significant NBD. According to this, a statistically significant difference was detected in all SF-36 subscales and MCS score $(P<0.05)$, except PF and RP subscales and PCS score in both groups $(P>0.05)$.

\section{Evaluation of sensitivity to change for NBD score}

When total NBD score before and after treatment was compared with Wilcoxon test, it was demonstrated that improvement in NBD score at the end of 2 months was significant $(P=0.011)$. Also, there was a statistically significant positive correlation between Global Rating of Change scale and the change in total NBD score at the end of 2 months $(r=0.821, P=0.007)$.

\section{DISCUSSION}

The main objective of this study was to establish the psychometric properties of the Turkish version of NBD score in patients with SCI, but also we believe that our study made a real contribution to the validation of the NBD score.

Cronbach alpha coefficient for internal consistency of NBD score was 0.547 . This indicates that the components of the score do not have a high degree of internal homogeneity. The reason behind this result could be the fact that NBD score evaluates both incontinence and constipation, does not contain subscales and has less number of questions. However, test-retest reliability of the Turkish version of NBD score was high.

While a significant relation was not detected between total NBD score and PCS in our study, there was a significant negative relation with MCS. Presence of a significant negative correlation between total NBD score and all subscales of SF-36 excluding PF and RP was demonstrated. Also when patient groups with mild and significant NBD were compared, there was a significant difference in all of SF-36 subscales excluding PF and RP. It was demonstrated that NBD had a greater influence on MCS than on PCS. These results suggest that NBD severity has a greater influence on mental health than physical health in patients with SCI.

In another study evaluating QoL in SCI, correlation between NBD and all domains of the SF-36 health questionnaire except PCS was reported similar to our results. ${ }^{31}$ There are, however, conflicting results in the literature. Liu et al. ${ }^{12}$ reported a significant relation between NBD score and PF and physical component summary score (PCS) and no significant difference in mental domains and MCS in their SCI population. In their study, $46.9 \%$ of the patients had moderate-severe NBD, and it was suggested that participants with worse NBD are likely to have less PF and PCS. In our study most of the patients had lower NBD scores, which may explain why we could not demonstrate any relationship between PF scores of SF-36 and NBD score. Furthermore, several items of the PF subscale of SF-36 are not sensitive to SCI-associated paralytic symptoms, which limits the use of SF-36 in populations with SCI. ${ }^{32}$

On the other hand, Fuhrer et al. ${ }^{33}$ demonstrated that the life satisfaction of persons with SCI was not affected by the degree of their disability. Post et al. ${ }^{34}$ reported that the level of social and psychological functioning is a more important predictor of life satisfaction rather than severity of injury. Thus, the mental condition gains importance for the QoL in SCI patients. These results may also explain our finding that the NBD score is closely associated with mental domains. Thus, severe NBD affects the QoL negatively, especially in mental terms.

Krogh demonstrated that the NBD score was significantly associated with self-reported impact on QoL. ${ }^{16}$ Similarly, we found a significant correlation between NBD score and the patient's subjective evaluation of the effect of bowel dysfunction on their QoL. Also, a significant association was detected between NBD score and Physician's Global Assessment in our study. As a result, the NBD score was also correlated with patient assessment of impact on QoL and PGA. These results support the construct validity of the score.

In the analysis of sensitivity to change, it was demonstrated that the NBD score could significantly detect the improvement in bowel dysfunction 2 months after treatment. Improvement in NBD score was also correlated with self-reported change in bowel dysfunction on GRC scale. Thus, the Turkish version of NBD score is sensitive to change and can be used to evaluate the response to the treatment or clinical changes.

The limitations of our study are the small sample size and no homogenous patient group in terms of severity and level of injury, as most subjects had mild NBD.

In conclusion, NBD score is a valid and reliable instrument and also sensitive to change in patients with SCI. It is suitable to be used in the assessment and follow-up of NBD symptoms of patients with SCI speaking Turkish. 
DATA ARCHIVING

There were no data to deposit.

\section{CONFLICT OF INTEREST}

The authors declare no conflict of interest.

\section{ACKNOWLEDGEMENTS}

We thank all the patients who participated in this study.

1 Krassioukov A, Eng JJ, Claxton G, Sakakibara BM, Shum S. Neurogenic bowe management after spinal cord injury: a systematic review of the evidence. Spinal Cord 2010; 48: 718-733.

2 Stone JM, Nino-Murcia M, Wolfe VA, Perkash I. Chronic gastrointestinal problems in spina cord injury patients: a prospective analysis. Am J Gastroenterol 1990; 85: 1114-1119.

3 Glickman S, Kamm MA. Bowel dysfunction in spinal cord injury patients. Lancet 1996; 347: 1651-1653.

4 Finnerup NB, Faaborg P, Krogh K, Jensen TS. Abdominal pain in long-term spinal cord injury. Spinal Cord 2008; 46: 198-203.

5 Krogh K, Nielsen J, Djurhuus JC, Mosdal C, Sabroe S, Laurberg S. Colorectal function in patients with spinal cord lesions. Dis Colon Rectum 1997; 40: 1233-1239.

6 Nino-Murcia M, Stone JM, Chang P, Perkash I. Colonic transit in spinal cord-injured patients. Invest Radiol 1990; 25: 109-112.

7 Bournet-Blanquart F, Weber J, Gouverneur JP, Dermangeon S. Large bowel transit time and anorectal manometric abnormalities in 19 patients with complete transection of the spinal cord. J Aut Nerv Syst 1990; 25: 109-112.

8 Menardo G, Bausano G, Corazziari E, Fazio A, Marangi A, Genta V et al. Large bowel transit in paraplegic patients. Dis Colon Rectum 1987; 30: 924-928.

9 Krogh K, Mosdal C, Laurberg S. Gastrointestinal and segmental colonic transit times in patients with acute and chronic spinal cord lesions. Spinal Cord 2000; 38: 615-621.

10 MacDonagh RP, Sun WM, Thomas DG, Smallwood R, Read NW. Anorectal function in patients with complete supraconal spinal cord lesions. Gut 1992; 33: 1532-1538.

11 Krogh K, Mosdal C, Gregersen H, Laurberg S. Rectal wall properties in patients with acute and chronic spinal cord lesions. Dis Colon Rectum 2002; 45: 641-649.

12 Liu CW, Huang CC, Yang YH, Chen SC, Weng MH, Huang Mh. Relationship between neurogenic bowel dysfunction and health-related quality of life in persons with spinal cord injury. J Rehabil Med 2009; 41: 35-40.

13 Agachan F, Chen T, Pfeiffer J, Reisman P, Wexner SD. A constipation scoring system to simplify evaluation and management of constipated patients. Dis Colon Rectum 1996; 39: 681-685.

14 Knowles CH, Eccersley AJ, Scott SM, Walker SM, Reeves B. Linear discriminant analysis of symptoms in patients with chronic constipation. Dis Colon Rectum 2000; 43: 1419-1426.

15 Vaizey CJ, Carapeti E, Cahill JA, Kamm MA. Prospective comparison of faecal incontinence grading systems. Gut 1999; 44: 77-80.

16 Krogh K, Christensen P, Sabroe S, Laurberg S. Neurogenic bowel dysfunction score. Spinal Cord 2006; 44: 625-631.
17 Tate DG, Forchheimer M, Rodriguez G, Chiodo A, Cameron AP, Meade M et al. Risk factors associated with neurogenic bowel complications and dysfunction in spinal cord injury. Arch Phys Med Rehabil 2016; 97: 1679-1686.

18 Adriaansen JJ, van Asbeck FW, van Kuppevelt D, Snoek GJ, Post MW. Outcomes of neurogenic bowel management in individuals living with a spinal cord injury for at least 10 years. Arch Phys Med Rehabil 2015; 96: 905-912.

19 Rasmussen MM, Kutzenberger J, Krogh K, Zepke F, Bodin C, Domurath B et al. Sacral anterior root stimulation improves bowel function in subjects with spinal cord injury. Spinal Cord 2015; 53: 297-301.

20 Awad RA, Santillán MC, Camacho S, Blanco MG, Domínguez JC, Pacheco MR. Recta hyposensitivity for non-noxious stimuli, postprandial hypersensitivity and its correlation with symptoms in complete spinal cord injury with neurogenic bowel dysfunction. Spinal Cord 2013; 51: 94-98.

21 Kwok S, Harvey L, Glinsky J, Bowden JL, Coggrave M, Tussler D. Does regular standing improve bowel function in people with spinal cord injury? A randomised crossover trial. Spinal Cord 2015; 53: 36-41.

22 Rasmussen MM, Krogh K, Clemmensen D, Tankisi H, Fuglsang-Frederiksen A, Rawashdeh $Y$ et al. The artificial somato-autonomic reflex arch does not improve bowel function in subjects with spinal cord injury. Spinal Cord 2015; 53: 705-710.

23 Rasmussen MM, Krogh K, Clemmensen D, Bluhme H, Rawashdeh Y, Christensen P. Colorectal transport during defecation in subjects with supraconal spinal cord injury. Spinal Cord 2013; 51: 683-687.

24 Mallek A, Jeribi S, Yaiich S, Eleuch H, Ghroubi S. Neurogenic bowel dysfunction translation and linguistic validation to classical Arabic. Ann Phys Rehabil Med 2016; 59S: e62-e63.

25 Krogh K, Emmanuel A, Perrouin-Verbe B, Korsten MA, Mulcahey MJ, Biering-Sørensen F. International spinal cord injury bowel function basic data set (Version 2.0). Spinal Cord 2017; 55: 692-698.

26 Koçyiğit H, Aydemir Ö, Fişek G, Ölmez N, Memiş A. Kısa Form-36 'nın Türkçe versiyonun güvenilirliği ve geçerliliği.Romatizmal hastalığı olan bir grup hasta ile çalıșma. İlaç ve Tedavi Derg 1992; 12: 102-106.

27 Beaton D, Bombardier C, Guillemin F, Ferraz M. Guidelines for the process of crosscultural adaptation of self-report measures. Spine 2000; 25: 3186-3191.

28 Gjersing L, Caplehorn J, Clausen T. Cross-cultural adaptation of research instruments: language, setting, time and statistical considerations. BMC Med Res Method 2010; 10: 13 .

29 Erdem D, Hava D, Keskinoğlu P, Bircan C, Peker Ö, Gülbahar S. Nörojenik Barsak Disfonksiyon Skorunun Türkçe Versiyonun Geliștirilmesi - Development of the Turkish version of neurogenic bowel dysfunction score. In: 25. Ulusal Fiziksel Tip ve Rehabilitasyon Kongresi, Özeti ve Tam Metin Kitabı, Antalya, Türkiye, 2015, pp 464-465 (P-190)

30 Jaeschke R, Singer J, Guyatt GH. Measurement of health status. Ascertaining the minimal clinically important difference. Control Clin Trials 1989; 10: 407-415.

31 Westgren N, Levi R. Quality of life and traumatic spinal cord injury. Arch Phys Med Rehabil 1998; 79: 1433-1439.

32 Tate DG, Kalpakjian CZ, Forchheimer MB. Quality of life issues in individuals with spinal cord injury. Arch Phys Med Rehabil 2002; 83: 18-25.

33 Further MJ, Rintala DH, Hart KA, Clearman R, Young ME. Relationship of life satisfaction to impairment, disability and handicap among persons with spinal cord injury. Arch Phys Med Rehabil 1992; 73: 552-557.

34 Post MW, De Witte LP, Van Asbeck FW, Van Dijk AJ. Predictors of health status and life satisfaction in spinal cord injury. Arch Phys Med Rehabil 1998; 79: 395-401. 